\title{
Isolation and identification of microflora from the midgut and salivary glands of Anopheles species in malaria endemic areas of Ethiopia
}

Abib Berhanu', Adugna Abera ${ }^{2 *}$ (D), Desalegn Nega², Sindew Mekasha², Surafel Fentaw ${ }^{3}$, Abebe Assefa ${ }^{3}$, Gashaw Gebrewolde ${ }^{4}$, Yonas Wuletaw ${ }^{2}$, Ashenafi Assefa ${ }^{2}$, Sisay Dugassa ${ }^{5}$, Habte Tekie ${ }^{1}$ and Geremew Tasew ${ }^{2}$

\begin{abstract}
Background: Anopheles mosquitoes are of great importance to human health. A number of studies have shown that midgut and salivary gland microflora have an impact on malaria parasite burden through colonization mechanisms, involving either direct Plasmodium microbiota interaction or bacterial-mediated induction of mosquito immune response. The objective of this study was to isolate and identify the microflora from the midgut and salivary glands of Anopheles species.

Methods: A total of 20 pools (ten per pool) from insectary-reared and 56 pools (five per pool) of field-collected Anopheles mosquitoes were anesthetized by chloroform and dissected. 70\% of ethanol was used for surface sterilization of mosquitoes and laboratory equipment, followed by rinsing Anopheles mosquitoes four times with $1 \mathrm{X}$ PBS. Each pool of dissected midgut and salivary gland sample was transferred in 1X PBS and squashed, incubated in the water bath and enriched in tryptic soya broth for $24 \mathrm{~h}$ at $35 \pm 2{ }^{\circ} \mathrm{C}$. As a control, the PBS solutions used to rinse the mosquitoes were also incubated in tryptic soya broth in the same conditions as the sample. After enrichment, a loopful of each sample was taken and inoculated on Blood, Chocolate, MacConkey, and Sabouraud Dextrose agar. Finally, the microbiota was isolated by colony characteristics, biochemical tests, and automated VITEK 2 Compact Analyzer.

Results: From all field and laboratory mosquitoes, Pseudomonas was found to be the dominant microbiota identified from all species of Anopheles mosquitoes. Acinetobacter and Klebsiellapneumonia and other families of gram-positive and gram-negative bacteria were identified.

Conclusions: A number of bacteria were isolated and identified. This is the first report on isolation and identification of microbiota from midgut and salivary glands of Anopheles species in Ethiopia. It can be used as a baseline for studying the relationship between microbiota and mosquitoes, and for the development of a new malaria biological control.
\end{abstract}

Keywords: Anopheles species, Identification, Microflora, Midgut, Salivary glands

\footnotetext{
* Correspondence: adugna.abera2020@gmail.com

${ }^{2}$ Malaria and Neglected Tropical Diseases Research Team, Ethiopian Public

Health Institute, P.O. Box: 1242, Addis Ababa, Ethiopia

Full list of author information is available at the end of the article
}

(c) The Author(s). 2019 Open Access This article is distributed under the terms of the Creative Commons Attribution 4.0 International License (http://creativecommons.org/licenses/by/4.0/), which permits unrestricted use, distribution, and reproduction in any medium, provided you give appropriate credit to the original author(s) and the source, provide a link to the Creative Commons license, and indicate if changes were made. The Creative Commons Public Domain Dedication waiver (http://creativecommons.org/publicdomain/zero/1.0/) applies to the data made available in this article, unless otherwise stated. 


\section{Background}

Malaria is an important vector borne disease caused by protozoan parasites in the genus Plasmodium. The Plasmodium species that cause human malaria are $P$. falciparum, $P$. ovale, $P$. malariae, $P$. vivax and $P$. knowlesi. These parasites are transmitted by infective bites of Anopheles mosquito vectors [1].

Malaria parasite transmission depends on the ability of mosquito vectors to support development of the parasites in the midgut and through to the infective sporozoite stages in their salivary glands [2]. However, commensal bacteria in the midgut can suppress parasite development and reduce the ability of mosquitoes to transmit the parasites to a new host, either by having direct anti-plasmodial effects or by stimulating basal immune responses of the mosquito against parasite development $[3,4]$. The bacterial microflora in the midgut of mosquitoes have different effects on parasite development, which is likely to differentially affect the vector competence of Anopheles mosquito species and the probability of disease transmission [3].

Studies conducted to isolate and identify bacterial species in field-collected Anopheles and Aedes mosquitoes using microbe culturing techniques reported the presence of a wide range of bacterial taxonomic groups in the midgut $[5,6]$. Similarly, a wide range of bacterial microflora including Pseudomonas cepacia, Entrobacter agglomerans and Flavobacterium species were identified in the midgut of three laboratory-reared Anopheles mosquito species [7]. Furthermore, the gut microflora varied depending on the sugar and blood feeding status of mosquitoes with reduced susceptibility of these mosquitoes to parasite development [7]. Moreover, midgut microfloral diversity depends on the ecological niche and geographical locations of vector mosquitoes. Straif and his colleagues [8] identified Enterobacter agglomerans and Escherichia coli as the most frequently isolated bacteria from midgut of field collected An. gambiae and An. funestus mosquitoes in Kenya and Mali.

The midgut microflora of Anopheles mosquitoes influence mosquito physiology, and also significantly alter vector competence [9]. As parts of the digestive system, the salivary glands harbor fewer bacterial microflora than the midgut of the mosquitoes [10]. However, Sharma et al. [11] showed that the salivary glands harbor more diverse microbial communities than the midgut in An. culicifacies.

Along with ecological factors such as sugar feeding, blood meals drastically alter mosquito gut microbial composition; these blood-fed midguts are enriched with Pseudomonas species [12]. These microbes in the gut of blood-fed mosquitoes may provide the additional genetic capacity to cope with oxidative stress due to catalase, manganese superoxidase dismutase, superoxide dismutase (Fe), heme oxygenase, alkyl hydroperoxide reductase (AhpC), and glutathione peroxidase enzymes in blood fed mosquitoes; such kind of genetic tolerance and fitness in mosquitoes is conferred by bacterial microflora in the stressful gut environment induced by a blood meal [12].

Thus, the resident microbiota in malaria vectors can enhance or suppress the development of the parasites that are to be transmitted to the mammalian host. Isolation and identification of microflora in the midgut and salivary glands of Anopheles mosquito species will provide data for further analysis of the tritrophic interaction of microbiota with the development of Plasmodium parasite in the mosquito vector for integrated malaria control in endemic areas. Therefore, the aim of this study was to assess, isolate and identify bacterial microflora from the midgut and salivary glands of laboratory-reared and field collected Anopheles mosquitoes in some malaria endemic areas of Ethiopia.

\section{Methods \\ Insectary and laboratory procedures for Anopheles arabiensis}

Mosquitoes were reared and maintained at $28 \pm 2{ }^{\circ} \mathrm{C} /$ and $80 \%$ relative humidity in Aklilu Lemma Institute of Pathobiology and Tropical and Infectious Disease Research Center (TIDRC) insectaries in Jimma. The insectaries were fitted with a simulated dawn and dusk machine which is essential for proper mating and feeding. For this study, 200 female An. arabiensis mosquitoes emerged after $24 \mathrm{~h}$. were transferred and kept in paper cups. Sterile cotton swabs were soaked with $10 \%$ sterile sucrose solution and changed every hour and placed on the mosquito cages until dissection.

\section{Mosquito processing from field collected Anopheles mosquitoes \\ Study area}

This study was done in Edo Kontola village, Adami Tullu Jiddo Kombolcha District, South- Central Ethiopia (Fig. 1). Lake Zeway, is the main environmental feature of the area, covers an area about 434 $\mathrm{km} 2$ with an average depth of $4 \mathrm{~m} \mathrm{[13].} \mathrm{The} \mathrm{sole} \mathrm{eco-}$ nomic activities of the society such as farms and fishing, are supported by this lake. During rainy season (June to October), people are usually cultivating maize and other cereal crops while onions, tomatoes, potatoes and green pepper are cultivated by irrigation during the dry season (November to May) as well as the wet season. 'Mana Chita' is the traditional African grass-thatched houses in which many of the inhabitants of the village live and some live in houses with corrugated iron roofs. The shoreline is the suitable potential mosquito breeding site in the area created 


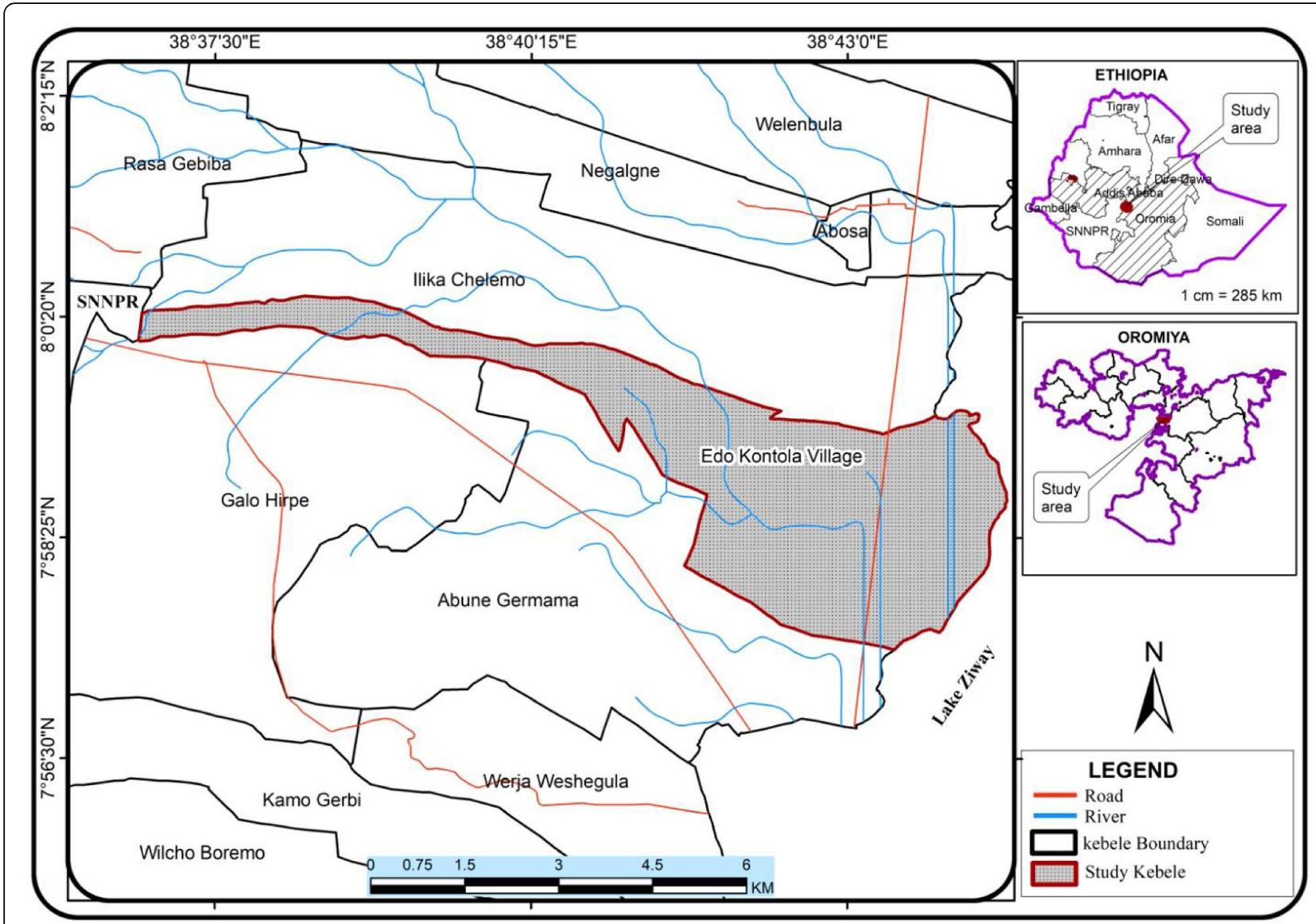

Fig. 1 The study map Edo Kontola, Adami Tulu Jiddo KombolchaDistrict, Oromia, Ethiopia (Prepared by Bamlaku Amente, Department of Geography and Environmental Studies, Addis Ababa University, based on Census data from Central Statistics Agency, 2017, Addis Ababa Ethiopia)

and maintained by the lake [14]. Consequently, mosquito number increases after the rainy season and declines as the lake volume lessens during the dry months.

\section{Ethical clearance}

Ethical clearance was obtained from the College of Natural and Computational Science Institutional Review Board (CNS-IRB; IRB/031/2018) and Ethiopian Public Health Institute Institutional Review Board (EPHI-IRB; SERO-049-03-2017) to conduct this research.

\section{Mosquito collection}

Four houses were selected for the night caught Anopheles mosquitoes collection using CDC light traps and Human landing Catch (HLC) from indoor and outdoor respectively. CDC light traps were selected for four houses which close to the lakeshore and irrigation fields and mosquitoes were collected from the lakeshore within walking distance less than or equal to $1 \mathrm{~km} \mathrm{[15].}$ On the other hand, human volunteers were used for
HLC mosquitoes collection which land on their exposed body parts from 19:00 to 06:00 for 50 min per each hour with a $10 \mathrm{~min}$ rest period.

For HLC, there were two collection shifts. One team collected from 19:00 to 24:00 whereas the second team from 24:00 to 06:00. To reduce position bias, two volunteers were rotated between indoor and outdoor positions and carried out the work in every hour. From each study house, there were $10 \mathrm{~m}$ gap between the position of outdoor collectors. Mosquitoes were captured as soon as they landed on the exposed foot to knee of each volunteer who did the collection using a flash light and mouth aspirator. Throughout the collection activities, the principal investigator coordinated and involved in the collection procedure and watched volunteers to ensure they did not fall asleep or get bitten by mosquitoes over the study nights [14]. In the following morning, mosquitoes were transported and their species was identified morphological characteristics using the standard identification key [16] at EPHI laboratory. 


\section{Mosquito processing for laboratory reared and field collected Anopheles mosquitoes}

A total of twenty pools of insectary-reared mosquitoes (10 per pool) and fifty-six pools of field- collected mosquitoes (5 per pool) were anesthetized by using a sterile cotton swab impregnated with chloroform. Throughout the dissection procedure in the laminar flow, the dissecting stereomicroscope $(1 \mathrm{X})$ working area, dissecting needles and forceps were dipped and sprayed in every dissection using 70\% ethanol. Prior to the midgut and salivary gland dissection, each pool of mosquitoes was surface sterilized by washing in 70\% ethanol followed by rinsing of each pool four times by $1 \mathrm{X}$ PBS. Each pool of dissected midgut and salivary glands was squashed and incubated in the water bath and transferred in $3 \mathrm{ml}$ of 1X PBS along with control solutions and incubated in a water bath $\left(27-31{ }^{\circ} \mathrm{C}\right)$ for $4 \mathrm{~h}$ until cultured in enriched Tryptic Soya Broth [17]. $1 \mathrm{ml}$ of each pool and control solutions were transferred into $3 \mathrm{ml}$ of Tryptic Soya Broth and incubated for $24 \mathrm{~h}$. at $35 \pm 2{ }^{\circ} \mathrm{C}$.

A loopful of each pool of turbid broth was inoculated on Blood, Chocolate, Mac Conkey and Sabouraud dextrose agar and incubated in carbon dioxide incubator (Blood and Chocolate media) and aerobic incubator (Mac Conkey and Sabouraud dextrose media) for $24 \mathrm{~h}$. at $35 \pm 2{ }^{\circ} \mathrm{C}$. For isolation of fungi from Sabouraud Dextrose media, the culture was incubated for fifteen days as fungi need more time to grow, and isolated based on their colony characteristics. Then, a wet film was used to identify yeast and other microbiota of fungi by observing under the microscope. Biochemical tests were done for other isolates from Blood, Mac Conkey, and Chocolate media.

Bacteria that could not be identified conventionally were analyzed and identified in VITEK 2 Compact (Biomerieux, France) which provides an automatic pipetting and dilution for identification of microbiota from the midgut and salivary glands of Anopheles mosquito samples. It has reagent cards with 64 wells for individual biochemical tests and has product type, lot number, expiration date, and a unique identifier that are linked to the sample. This machine requires pure colonies suspended in $3 \mathrm{ml}$ of sterile aqueous $0.45 \%$ saline in $12 \times 75 \mathrm{~mm}$ clear plastic tubes. Turbidity was adjusted to 0.5 McFarland to get a standardized microbial load in the given sample. The tubes containing sample suspension were placed in a special rack (Cassette) which accommodates up to 10 tests. All cards were incubated at $35 \pm 1{ }^{\circ} \mathrm{C}$. Data was collected at 15 -min intervals during the entire incubation period. In this machine, test reaction results appeared as "+" or "- " and an identification level above 95\% considered as an excellent identification, and at least three organisms having the same biochemical reactions in the database or weak reaction and do not correspond to any taxon in the database considered as unidentified organisms.

\section{Results \\ Microbiota composition in Anopheles arabiensis from insectary}

Of 200 female An. arabiensis, a total of 110 microflora colonies from both midgut and salivary glands were counted. Of these, 97 represent 14 species of microflora including: Klebsiella pneumonia, Saccharomyces cerevisiae, Serratia marcescens, Staphylococcus epidermidis, Pseudomonas luteola, Pseudomonas aeruginosa, Kocuria rhizophila, Streptococcus thoraltensis, Methylobacterium lacunta, Enterococcus casseliflavus, Kytococcus sendntarius, Lactococcus garvieae, Kocuria kristinae and Alloiococcus otitis. The remaining 13 microflora colonies were identified at the genus level including Pseudomonas (nine isolates), Bacillus (one) and Acinetobacter (three). Table 1 shows the number of isolates and prevalence of microbiota identified from both midgut and salivary glands of $A n$. arabiensis from the two insectaries. From a total of 47 identified microflora, 19\% were Saccharomyces cerevisiae (Table 1). Similarly, Pseudomonas spp. comprised $19 \%$ of the total identified microflora. Serratia marcescens was the second most abundant microbiota comprised $13 \%$ of the total species which were isolated from 14 isolates. Acinetobacter and Streptococcus thoraltensis were comprised $6 \%$ of the total identified bacteria. Lactococcus and Enterococcus were identified in both midgut and salivary glands of $A n$. arabiensis and comprise 11 and $4 \%$ respectively. K. pneumonia, S. epidermidis, $P$. aeruginosa, Bacillus species were the least identified microbiota. Besides, the results from the four control solutions were found to be Erythrobacter and Bacillus species analyzed by VITEK 2 Compact automation machine.

\section{Microbiota composition from field collected Anopheles mosquitoes species}

During the three nights of collection of CDC light trap and human landing catches, a total of 280 female anopheline mosquitoes were captured. An. zeimanni (140) was the dominant species followed by An. gambiae s.l. (60), An. pharoensis (45) and An. funestus (35). Overall, 180 mosquitoes were captured outdoors and 100 indoors. A total of fifty six pools of mosquitoes, five mosquitoes per pool: five fed, five gravid and five unfed from midgut and salivary glands of each species of Anopheles mosquitoes were analyzed.

A total of 280 Anopheles mosquito midgut and salivary gland samples were analyzed. The samples were dissected and screened on four culture media resulting in a total of 68 microflora isolates. Fifty-three isolates were members of three genera and 5 species of gram negative 
Table 1 The total number of isolates and microbiota identified from midgut and salivary glands of laboratory reared An. arabiensis

\begin{tabular}{|c|c|c|c|c|c|}
\hline \multirow[t]{2}{*}{ Bacterial species identified } & \multirow{2}{*}{$\begin{array}{l}\text { Total \# } \\
\text { of } \\
\text { isolates }\end{array}$} & \multicolumn{2}{|c|}{ Source of microbiota identified } & \multirow[b]{2}{*}{ Total } & \multirow{2}{*}{$\begin{array}{l}\text { Percent } \\
(n=47)\end{array}$} \\
\hline & & Midgut & Salivary glands & & \\
\hline Klebsiella pneumonia $^{+\dagger}$ & 2 & 0 & 1 & 1 & 2 \\
\hline Saccharomyces cerevisiae & 22 & 3 & 6 & 9 & 19 \\
\hline Serratia marcescens ${ }^{\dagger \dagger}$ & 14 & 3 & 3 & 6 & 13 \\
\hline Staphylococcus epidermidis $^{\dagger}$ & 2 & 0 & 1 & 1 & 2 \\
\hline Pseudomonas luteola ${ }^{\dagger+}$ & 2 & 1 & 0 & 1 & 2 \\
\hline Pseudomonas aeruginosa ${ }^{\dagger+}$ & 2 & 1 & 0 & 1 & 2 \\
\hline Kocuria rhizophila ${ }^{\dagger}$ & 2 & 0 & 1 & 1 & 2 \\
\hline Streptococcus thoraltensis $^{\dagger}$ & 8 & 2 & 1 & 3 & 6 \\
\hline Methylobacterium lacunta ${ }^{+\dagger}$ & 2 & 0 & 1 & 1 & 2 \\
\hline Enterococcus casseliflavus $^{\dagger}$ & 5 & 2 & 0 & 2 & 4 \\
\hline Kytococcus sedentarius $^{\dagger}$ & 2 & 1 & 0 & 1 & 2 \\
\hline Lactococcus garvieae $^{\dagger}$ & 12 & 3 & 2 & 5 & 11 \\
\hline Kocuria kristinae $^{\dagger}$ & 2 & 1 & 0 & 1 & 2 \\
\hline Alloiococcus otitis $^{\dagger}$ & 2 & 1 & 0 & 1 & 2 \\
\hline Pseudomonas spp. ${ }^{+\dagger}$ & 22 & 4 & 5 & 9 & 19 \\
\hline 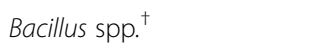 & 2 & 0 & 1 & 1 & 2 \\
\hline \multirow[t]{2}{*}{ Acinetobacter spp. ${ }^{\dagger+}$} & 7 & 0 & 3 & 3 & 6 \\
\hline & & & & 47 & \\
\hline
\end{tabular}

Note: $\dagger$ is gram positive bacteria species/genera, $+\dagger$ is gram negative bacteria species/genera

bacteria, and the remaining 15 isolates of 4 species belonged to gram positive bacteria. Both gram negative and gram positive bacteria were isolated from fed, gravid and unfed Anopheles mosquitoes. Table 2 shows the abdominal conditions, sources of samples and Anopheles mosquitos' species with their conventional biochemical test results along with their identified bacterial species.

A total of 9 bacterial species were identified from the four collected Anophelesspecies (Table 2 and Table 3). According to the number of isolated and identified species, it was shown that, An.gambiae s.l. had a higher diversity of bacteria with 7 species isolated from fed salivary glands, gravid salivary glands, fed and unfed midgut; divided in 6 genera of bacteria. In contrast, An.funestus had only two species from two genera identified: Serratia and Streptococcus. Surprisingly, Serratia fonticola was identified from unfed An. pharoensis, $A n$. zeimanni and An.gambiae s.l.(Table 3). The genus Pseudomonaswas the most frequently isolated bacteria in this study, found in 32 of the 68 isolates. In the conventional biochemical test, there were no fungal or yeast isolates found from Sabouraud Dextrose Agar media. From the control cultured rinsed solutions, Erythrobacter and $\mathrm{Ba}$ cillus species were screened by VITEK 2 Compact automation machine. Moreover, conventionally unidentified microorganisms were identified by VITEK 2 Compact automation machine (Table 3).

\section{Discussion}

The present study isolated and identified resident aerobic and salivary gland bacterial microbiota from laboratory reared Anopheles arabiensis, and from field collected of Anopheles mosquitoes, including An. gambiae s.l., An. zeimanni, An. pharoensis and An. funestus from some endemic areas in Ethiopia.

The composition of isolates in this study showed that gram negative bacteria dominate the midgut and salivary gland flora of both laboratory reared and field collected Anopheles mosquito species (Table 1and 2). This agrees with earlier results from culture-based studies from different geographical areas on An. stephensi, An. maculipennis and other Anopheles mosquito species [18, 19], and on Anopheles stephensi and Anopheles gambiae [20]. Similar findings have also been reported from sequence-based studies on $A n$. darlingi [21] and $A n$. gambiae [15]. Some bacteria are common residents in the midugut and salivary glands of several Anopheles species from different ecological settings. For instance, the genus Serratia has been isolated from An. stephensi in India [22], from An. culicifacies in Iran [23], and from An. gambiae in Zambia [24]. This genus is identified from midgut and salivary glands of laboratory reared $A n$. arabiensis, as well as from midgut of field collected gravid An. funestus and blood fed An. zeimanni, respectively, in the present study. 
Table 2 Biochemical test results of conventional culture method after $24 \mathrm{~h}$ incubation

\begin{tabular}{|c|c|c|c|c|c|c|c|c|c|c|c|}
\hline \multirow{3}{*}{$\begin{array}{l}\text { Anopheles } \\
\text { species }\end{array}$} & \multirow{3}{*}{$\begin{array}{l}\text { Abdominal } \\
\text { condition }\end{array}$} & \multirow{3}{*}{$\begin{array}{l}\text { Sources of } \\
\text { samples }\end{array}$} & \multicolumn{7}{|c|}{ Biochemical tests } & \multirow[t]{3}{*}{ Additional } & \multirow[t]{3}{*}{ Identified bacteria } \\
\hline & & & \multirow[t]{2}{*}{$\overline{L D C}$} & \multirow[t]{2}{*}{ CIT } & \multirow[t]{2}{*}{ TSIA } & \multicolumn{2}{|l|}{ SIM } & \multirow[t]{2}{*}{ UREA } & \multirow[t]{2}{*}{$\overline{\mathrm{H}_{2} \mathrm{~S}}$} & & \\
\hline & & & & & & Motility & Indole & & & & \\
\hline \multirow[t]{2}{*}{$\begin{array}{l}\text { Anopheles } \\
\text { funestus }\end{array}$} & $\begin{array}{l}\text { Fed Gravid } \\
\text { Unfed }\end{array}$ & $\begin{array}{l}\text { Midgut Salivary } \\
\text { gland }\end{array}$ & -ve & +ve & -ve & -ve & -ve & -ve & -ve & $\mathrm{Cat}^{+}, \mathrm{Oxi}^{+}$ & 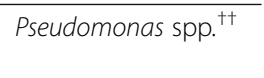 \\
\hline & Gravid & S. gland & -ve & + ve & + ve & +ve & -ve & +ve & + ve & $\mathrm{Cat}^{+}, \mathrm{Oxi}^{-}$ & 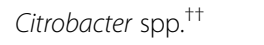 \\
\hline \multirow{4}{*}{$\begin{array}{l}\text { Anopheles } \\
\text { pharoensis }\end{array}$} & \multirow[t]{2}{*}{ Fed } & \multirow[t]{2}{*}{ S. gland } & -ve & + ve & -ve & -ve & -ve & +ve & -ve & $\mathrm{Cat}^{+}, \mathrm{Oxi}^{-}$ & Klebsiella ozane $e^{+\dagger}$ \\
\hline & & & -ve & + ve & -ve & + ve & -ve & + ve & -ve & $\mathrm{Cat}^{+}, \mathrm{Oxi}^{-}$ & Providencia rettgerit ${ }^{\dagger \dagger}$ \\
\hline & \multirow{2}{*}{$\begin{array}{l}\text { Gravid Unfed } \\
\text { Unfed }\end{array}$} & Midgut & -ve & + ve & -ve & -ve & -ve & -ve & -ve & $\mathrm{Cat}^{+}, \mathrm{Oxi}^{+}$ & Pseudomonas spp. ${ }^{+\dagger}$ \\
\hline & & S. gland & + ve & +ve & -ve & -ve & -ve & -ve & -ve & $\mathrm{Cat}^{+}, \mathrm{Oxi}^{-}$ & Acinetobacter spp..$^{+\dagger}$ \\
\hline \multirow{6}{*}{$\begin{array}{l}\text { Anopheles } \\
\text { gambiae s.l }\end{array}$} & Fed & S. gland & -ve & + ve & + ve & +ve & -ve & +ve & -ve & $\mathrm{Cat}^{+}, \mathrm{Oxi}^{-}$ & Enterobacter cloacae ${ }^{\dagger \dagger}$ \\
\hline & Fed & Midgut S. gland & -ve & $+v e$ & -ve & -ve & -ve & -ve & -ve & $\mathrm{Cat}^{+}, \mathrm{Oxi}^{+}$ & Pseudomonas spp. ${ }^{+\dagger}$ \\
\hline & \multirow[t]{2}{*}{ Gravid } & Midgut S. gland & -ve & $+v e$ & -ve & -ve & -ve & -ve & -ve & $\mathrm{Cat}^{+}, \mathrm{Oxi}^{+}$ & Pseudomonas spp. ${ }^{+\dagger}$ \\
\hline & & S. gland & + ve & + ve & + ve & -ve & -ve & +ve & -ve & $\mathrm{Cat}^{+}, \mathrm{Oxi}^{-}$ & Klebsiella pneumonia $^{\dagger+}$ \\
\hline & \multirow[t]{2}{*}{ Unfed } & Midgut & -ve & +ve & -ve & -ve & -ve & -ve & -ve & $\mathrm{Cat}^{+}, \mathrm{Oxi}^{+}$ & Pseudomonas spp. ${ }^{+\dagger}$ \\
\hline & & S. gland & + ve & +ve & +ve & -ve & -ve & +ve & -ve & $\mathrm{Cat}^{+}, \mathrm{Oxi}^{-}$ & Klebsiella pneumonia $^{\dagger+}$ \\
\hline \multirow{6}{*}{$\begin{array}{l}\text { Anopheles } \\
\text { zeimanni }\end{array}$} & Fed & Midgut & + ve & $+v e$ & -ve & -ve & -ve & -ve & -ve & $\mathrm{Cat}^{+}, \mathrm{Oxi}^{-}$ & Acinetobacter spp. ${ }^{+\dagger}$ \\
\hline & $\begin{array}{l}\text { Fed unfed } \\
\text { gravid }\end{array}$ & Midgut S. gland & -ve & + ve & -ve & -ve & -ve & -ve & -ve & $\mathrm{Cat}^{+}, \mathrm{Oxi}^{+}$ & 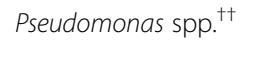 \\
\hline & $\begin{array}{l}\text { Gravid } \\
\text { Unfed }\end{array}$ & S. gland Midgut & + ve & +ve & +ve & -ve & -ve & +ve & -ve & $\mathrm{Cat}^{+}, \mathrm{Oxi}^{-}$ & Klebsiella pneumonia $^{\dagger+}$ \\
\hline & \multirow[t]{2}{*}{ Gravid } & \multirow[t]{2}{*}{ S. gland } & -ve & + ve & + ve & +ve & -ve & +ve & + ve & $\mathrm{Cat}^{+}, \mathrm{Oxi}^{-}$ & 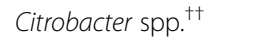 \\
\hline & & & +ve & $+v e$ & -ve & -ve & -ve & -ve & -ve & $\mathrm{Cat}^{+}, \mathrm{Oxi}^{-}$ & Acinetobacter spp. ${ }^{+\dagger}$ \\
\hline & Unfed & Midgut & -ve & + ve & + ve & + ve & -ve & + ve & + ve & $\mathrm{Cat}^{+}, \mathrm{Oxi}^{-}$ & Citrobacter spp. ${ }^{+\dagger}$ \\
\hline
\end{tabular}

Note: LDC Lysine decarboxylase, CIT Citrate, TSIA Triple Sugar Iron Agar, SIM Sulfur Indole Motility Media, $\mathrm{H}_{2} \mathrm{~S}$ Hydrogen sulfide t† is gram negative bacteria species/genera

In the present study, Pseudomonas were the most frequently isolated bacteria from laboratory reared $A n$. arabiensis (Table 1), and from field collected $A n$. funestus, An. pharoensis, An. zeimanni and An. gambiae s.l. (Table 2). This genus has been commonly isolated in several mosquito vectors in Asia and the Americas [23, 25]. However, it was isolated at a low level in mosquitoes in Kenya [3]. Previous findings reported the genera Pseudomonas, Serratia and Acinetobacter in the midgut while Pseudomonas and Acinetobacter were identifiedfrom the salivary glands of Anopheles mosquitoes [26].

In addition to bacteria, fungi are common microbiota frequently isolated from the mosquito larvae in aquatic breeding habitats and, from adults either through ingesting fungi in a sugar meal or through external physical contact with fungal spores [27]. As a result, the mosquito midgut and other tissues have been parasitized by common fungal genera Beauveria and Metarhizium [28]. In this study, a total of nine Saccharomyces yeasts species were identified from 22 microflora colonies of laboratory reared An. arabiensis (Table 1). Of these, six Saccharomyces species were isolated from salivary glands and three Saccharomyces species were isolated from the midgut cultures of $A n$. arabiensis. These results are in line with the findings on isolation of yeasts from laboratory reared and field collected Anopheles mosquitoes [29].

In this study, Serratia marcescens and Streptococcus mitis were identified from midgut cultures of gravid $A n$. funestus and An. gambiae s.l., respectively. In addition, Staphylococcus epidermidis and Enterobacter cloacae isolates were identified from the midgut of unfed $A n$. pharoensis, salivary glands of laboratory reared Anopheles arabiensis, and from midgut of field collected gravid $A n$. gambiae s.l. In contrast to these findings, Staphylococcus epidermidis and Enterobacter cloacae were the dominantisolated bacteria from the midgut of fed An. gambiae and based on molecular analysis and cultures of fed and gravid An. gambiae microbiota indicated that Serratia marcescens and Streptococcus mitis were the dominant isolates from An. gambiae [30].

Anopheles mosquitoes harbor diverse microbiota which affects their physiology, metabolism and immune processes. Midgut and salivary gland microbiota in mosquitoes also affect the outcome of the mosquito infection with the Plasmodium parasites [31]. A recent study based on metagenomic analysis combined with culture 
Table 3 The summarized result of microbiota identified by Vitek 2 Compact from Adami Tullu, Jido Kombolcha District

\begin{tabular}{|c|c|c|c|}
\hline $\begin{array}{l}\text { Anopheles } \\
\text { species }\end{array}$ & $\begin{array}{l}\text { Feeding } \\
\text { stages }\end{array}$ & Source of samples & Identified microbiota \\
\hline \multirow[t]{3}{*}{ An. funestus } & Fed & $\mathrm{sg}$ & Unidentified \\
\hline & Gravid & $\mathrm{mg}$ & Ser. marcescens ${ }^{\dagger+}$ \\
\hline & Unfed & $\mathrm{sg}$ & Str. thoraltensis ${ }^{\dagger}$ \\
\hline \multirow[t]{3}{*}{ An. pharoensis } & Fed & $\mathrm{mg}$ & Unidentified \\
\hline & Unfed & $\mathrm{mg}$ & Staph. epidermidis ${ }^{\dagger}$ \\
\hline & Unfed & $\mathrm{sg}$ & Serratia fonticola ${ }^{+\dagger}$ \\
\hline \multirow[t]{6}{*}{ An. zeimanni } & Fed & $\mathrm{mg}$ & Ser. marcescens ${ }^{\dagger+}$ \\
\hline & Gravid & $\mathrm{mg}$ & Str. thoraltensis ${ }^{\dagger}$ \\
\hline & Gravid & $\mathrm{mg}$ & Str. thoraltensis ${ }^{\dagger}$ \\
\hline & Fed & $\mathrm{sg}$ & Str. thoraltensis ${ }^{\dagger}$ \\
\hline & Unfed & $\mathrm{sg}$ & Str. thoraltensis ${ }^{\dagger}$ \\
\hline & Unfed & $\mathrm{mg}$ & Ser. fonticola ${ }^{+\dagger}$ \\
\hline \multirow[t]{6}{*}{ An. gambiae s.l. } & Fed & $\mathrm{mg}$ & Str. thoraltensis ${ }^{\dagger}$ \\
\hline & Gravid & $\mathrm{mg}$ & Str. mitis/oralis ${ }^{\dagger}$ \\
\hline & Gravid & $\mathrm{sg}$ & Staph. aureus ${ }^{\dagger}$ \\
\hline & Unfed & $\mathrm{mg}$ & Ser. fonticola ${ }^{\dagger \dagger}$ \\
\hline & Unfed & $\mathrm{sg}$ & Str. thoraltensis ${ }^{\dagger}$ \\
\hline & Fed & $\mathrm{mg}$ & Enterococcus faecium $^{\dagger}$ \\
\hline Control & \multicolumn{2}{|c|}{ The four PBS rinsed solutions } & $\begin{array}{l}\text { Erythrobacter and } \\
\text { Bacillus species }\end{array}$ \\
\hline
\end{tabular}

Note: $\dagger$ is gram positive bacteria species, $+\dagger$ is gram negative bacteria species $\mathrm{mg}$ is midgut, $\mathrm{sg}$ is salivary glands

methods provided an insight in to the role of the Anopheles-associated microbiota in modulating the immune system of the vector mosquitoes and affect parasite development and disease transmission. Among these Anopheles-associated microbiota: Lactococcus garvieae, Kocuria kristinae, Enterococcus casseliflavus and Methylobacterium lacunta were identified from the body of Anopheles mosquitoes from different geographical locations [32]. These bacterial species were consistently isolated and identified from salivary gland and midgut cultures of laboratory reared $A n$. arabiensis in the present study.

\section{Conclusions}

This study describes isolation and identification of microbiota in the midgut and salivary glands of $A n$. arabiensis from insectary and field collected Anopheles species. To our knowledge, it is the first study providing an in depth description of the microbiota diversity in midgut and salivary glands of Anopheles mosquitoes. Our findings indicated that, Pseudomonas species had the dominant microbiota identified from all species of field collected Anopheles mosquitoes and insectaries. Moreover, An. arabiensis has a more diversified microbiota compared to the other species.

\section{Abbreviations}

CDC: Center for Disease Control and Prevention; CIT: Citrate; EPHI: Ethiopian Public Health Institute; HLC: Human Landing Catch; LDC: Lysine decarboxylase; PBS: Phosphate Buffer Saline; SIM: Sulfur indole motility media; TIDRC: Tropical and Infectious Disease Research Center; TSIA: Triple sugar iron agar

\section{Acknowledgements}

The authors are thankful to Ethiopian Public Health Institute, Malaria and Neglected Tropical Diseases Research for financing the work; Professor Dilnesaw Yehualaw and Dr. Meshesha Balkaw for their willingness to provide female Anopheles mosquitoes from their respective insectaries; English reviewed by Tsion Gebremdehen; EPHI, Clinical Bacteriology and Mycology Research Team for kind provision of laboratory items and reagents and all technical staff of Jimma, Adama and Aklilu Lemma Institute of Pathobiology insectaries who assisted us technically until laboratory processing. The authors would also like duly acknowledge Mr. Bamlaku Amente, Department of Geography and Environmental Studies, Addis Ababa University, for preparing the map of the study area and his unreserved permission for publication in open access journal.

\section{Funding}

This study was supported from the core budget of Ethiopian Public Health Institute, therapeutic efficacy study of malaria. The funding body was not involved in the design of the study and collection, analysis, and interpretation of data and in writing the manuscript.

\section{Availability of data and materials}

The datasets generated and analyzed during this study are available from the corresponding author upon reasonable request.

\section{Authors' contributions}

All authors read and approved the final version of the manuscript. AA and GT conceived and generated the idea, $A A, A B, G T$, and DN drafted the study proposal. AA, GT, AB, SD, HT, DN, SM, YW and AshA participated in proposal developments and manuscript writes up. $A B$ and $A A$ drafted the manuscript. $A B, S F, A A$ and $G G$ performed field and laboratory experiments.

\section{Ethics approval and consent to participate}

Ethical clearance was obtained from the College of Natural and Computational Science Institutional Review Board (CNS-IRB; IRB/031/2018) and Ethiopian Public Health Institute Institutional Review Board (EPHI-IRB; SERO-049-03-2017) to conduct this research.

\section{Consent for publication}

All authors of this manuscript have read and approved the final version of this manuscript and have given their consent for publication.

\section{Competing interests}

The authors declare that they have no competing interests.

\section{Publisher's Note}

Springer Nature remains neutral with regard to jurisdictional claims in published maps and institutional affiliations.

\section{Author details}

${ }^{1}$ Insect Science Stream, Department of Zoological Sciences, College of Natural and Computational Sciences, Addis Ababa University, Addis Ababa, Ethiopia. ${ }^{2}$ Malaria and Neglected Tropical Diseases Research Team, Ethiopian Public Health Institute, P.O. Box: 1242, Addis Ababa, Ethiopia. ${ }^{3}$ Clinical Bacteriology and Mycology Research Team, Ethiopian Public Health Institute, Addis Ababa, Ethiopia. ${ }^{4}$ Vaccine and Diagnostic Research Team, Ethiopian Public Health Institute, Addis Ababa, Ethiopia. ${ }^{5}$ Vector Biology and Control Research Unit, Aklilu Lemma Institute of Pathobiology, Addis Ababa, Ethiopia.

Received: 4 July 2018 Accepted: 11 April 2019

Published online: 29 April 2019

\section{References}

1. Cox FE. History of the discovery of the malaria parasites and their vectors. Parasit Vectors. 2010;3(1):1-5. 
2. Omumbo J, Snow RW, Gouws E, Rapuoda B, Craig MH, Tanser FC, et al. Models to predict the intensity of Plasmodium falciparum transmission applications to the burden of disease in Kenya. Trans R Soc Trop Med Hyg 1998:92(6):1-3.

3. Osei-PokuJ, Mbogo C, Palmer W, Jiggins F. Deep sequencing reveals extensive variation in the gut microbiota of wild mosquitoes from Kenya. Mole Ecolo 2012; 21: 5138-5150.

4. Dong Y, Manfredini F, Dimopoulos G. Implication of the mosquito midgut microbiota in the defense against malaria parasites. PLoS Pathog. 2009;5(5): e1000423.

5. Ngo CTN, Aujoulant F, Veas F, Jumas-Bilak E, Manguin S. Bacterial diversity associated with wild caught Anopheles mosquitoes from Dak Nong Province, Vietnam using culture and DNA fingerprint. PLoS One. 2015;10(3): e0118634.

6. Gusmao DS, Santos VA, Marinic DC, Jr MB, Berbert-Molina MA, Lemos FJA. Culture-dependent and culture-independent characterization of microorganisms associated with Aedesaegypti (Diptera: Culicidae) $(\mathrm{L})$ and dynamics of bacterial colonization in the midgut. Acta Trop. 2010;115(1): 275-81.

7. Pumpuni CB, Demaio J, Kent M, Davis JR, Beier JC. Bacterial population dynamics in three Anopheles species: the impact on Plasmodium sporogonic development. Am J TropMed Hyg 1996; 54 (2): 214-218.

8. Straif SC, Mbogo CN, Toure AM, Walker ED, Kaufman M, Toure YT Beier JC Mid gut bacteria in Anopheles gambiae and An. Funestus (Diptera: culicidae) from Kenya and Mali. JMed Entomol. 1998;35(3):222-6.

9. Dennison NJ, Jupatanakul N, Dimopoulos G. The mosquito microbiota influences vector competence for human pathogens. Curr Opin Insect Sci. 2014;1(3):6-13.

10. Minard G, Mavingui $P$, Moro CV. Diversity and function of bacterial mcrobiota in the mosquito holobiont. Parasit Vectors. 2013;6:146.

11. Sharma P, Sharma S, Maurya RK, De TD, Thomas T, Lata S, et al. Salivary glands harbor more diverse microbial communities than gut in Anopheles culicifacies. Parasit Vectors. 2014;7(1):230-5.

12. Alvarez C, Kukutla P, Jiang J, Yu W, Xu J. Draft genome sequence of Pseudomonas sp. strain Ag1, isolated from the midgut of the malaria mosquito Anopheles gambiae. J Bacteriol. 2012;194(19):5442-9.

13. Abose T, Ameneshewa B, Teklehaimanot A. Cytogenetic studies on theAnopheles gambiae complex species in Ethiopia. Eth J Health Devt. 1998; 12:81-3.

14. Kenea O, Balkaw M, Tekie H, Gebre-Michael T, Deressa W, Loha E, et al. Human-biting activities of Anopheles species in south-Central Ethiopia. Parasit Vectors. 2016;9:527.

15. Deressa W, Loha E, Balkew M, Hailu A, Gari T, Kenea O, et al. Combining long-lasting insecticidal nets and indoor residual spraying for malaria prevention in Ethiopia: study protocol for a cluster randomized controlled trial. Bio Med Central. 2016;17:20.

16. Gillies MT, Coetzee M. A supplement to the anophelinae of Africa south of the Sahara (Afrotropical region). 3rd ed. Johannesburg: The South African Institute for Medical Research Press; 1987.

17. Christiansen-Jucht C, Parham PE, Saddler A, Koella JC, Basaneg MG. Temperature during larval development and adult maintenance influences the survival of Anopheles gambiae s.s. Parasit Vectors. 2014;7:489.

18. Djadid ND, Jazayeri H, Raz A, Favia G, Ricci I, Zakeri S. Identification of the midgut microbiota of An. stephensi and An. maculipennis for their application as a paratransgenic tool against malaria. PLoS One. 2011;7(1): e28484.

19. Rami A, Raz A, Zakeri S, Djadid ND. Isolation and identification of Asaia sp. in Anopheles spp. mosquitoes collected from Iranian malaria settings: steps toward applying paratransgenic tools against malaria. Parasit Vectors. 2018;11:367.

20. Damiani C, Ricci I, Crotti E, Rossi P, Rizzi A, Scuppa P, et al. Mosquitobacteria Symbiosis: the case of Anopheles gambiae and Asaia. Microb Ecol. 2010;60:644-54

21. Malafronte RDS, Marrelli M, Marinotti O. Analysis of ITS2 DNA sequences from Brazilian Anopheles darlingi (Diptera: Culicidae). J Med Entomol. 1999; 36(5):631-4

22. Rani A, Sharma A, Rajagopal R, Adak T, Bhatnagar R. Bacterial diversity analysis of larvae and adult midgut microflora using culture-dependent and culture-independent methods in lab-reared and field-collected Anopheles stephensi-an Asian malarial vector. BMC Microbiol. 2009;9:96.

23. Chavshin AR, Oshaghi MA, Vatandoost H, Pourmand MR, Raeisi A, Terenius O. Isolation and identification of culturable bacteria from wild Anopheles culicifacies, a first step in a paratransgenesis approach. Parasit Vectors. 2014; 7:419.

24. Cirimotich CM, Dong Y, Clayton AM, Sandiford SL, Souza-Neto JA, Mulenga $M$, et al. Natural microbe-mediated refractoriness to Plasmodium infection in Anopheles gambiae. PMC. 2011;332(6031):855-8.

25. Terenius O, De Oliveira CD, Pinheiro WD, Tadei WP, James AA, Marinotti O. 165 rRNA gene sequences from bacteria associated with adult Anopheles darlingi (Diptera: Culicidae) mosquitoes. J Med Entomol. 2008;45(1):172-5.

26. Tchioffo MT, Boissiere A, Abate L, Nsango SE, Bayibeki AN. Awono-Ambene et al. dynamics of bacterial community composition in the malaria mosquitoe's epithelia. Front Microbiol. 2016:6:1-8.

27. Lynch PA, Grimm U, Thomas MB, Read AF. Prospective malaria control using entomopathogenic fungi: comparative evaluation of impact on transmission and selection for resistance. Malar J. 2012;28(11):466-70.

28. Scholte E-J, Knols BGJ, Samson RA, Takken W. Entomopathogenic fungi for mosquito control: a review. J Insect Sci. 2004;4(1):1-19.

29. Cappelli A, Ulissi U, Valzano M, Damiani C, Epis S, Gabrielli MG, et al. A Wickerhamomyces anomalus killer strain in the malaria vector Anopheles stephensi. PLoS One. 2014;9(5):e95988.

30. Tandina F, Almeras L, Kone AK, Doumbo OK, Raoult D, Parola P. Use of MALDI-TOF MS and culturomics to identify mosquitoes and their midgut microbiota. Parasit Vectors. 2016:9:495.

31. Gonzalez-Ceron L, Santillan F, Rodriguez MH, Mendez D, Hernandez-Avila JE. Bacteria in midguts of field-collected Anopheles albimanus block Plasmodium vivax sporogonic development. J Med Entomol. 2003;40(3):371-4.

32. Villegas LM, Pimenta PFP. Metagenomics, paratransgenesis and the Anopheles microbiome: a portrait of the geographical distribution of the anopheline microbiota based on a meta-analysis of reported taxa. Mem Inst Oswaldo Cruz. 2014;109(5):672-84.

\section{Ready to submit your research? Choose BMC and benefit from:}

- fast, convenient online submission

- thorough peer review by experienced researchers in your field

- rapid publication on acceptance

- support for research data, including large and complex data types

- gold Open Access which fosters wider collaboration and increased citations

- maximum visibility for your research: over $100 \mathrm{M}$ website views per year

At BMC, research is always in progress.

Learn more biomedcentral.com/submissions 